\title{
КОМПЛЕКСНОЕ ИСПОЛЬЗОВАНИЕ НЕКОНДИЦИОННОГО НЕФРИТА
}

\author{
Худякова Людмила Ивановна ${ }^{1}$ \\ Ikhud@binm.ru
}

\author{
Кислов Евгений Владимирович², \\ evg-kislov@yandex.ru
}

\author{
Палеев Павел Леонидович 1 , \\ palpavel@mail.ru
}

\author{
Малышев Алексей Владимирович2, \\ Waylander6@mail.ru \\ 1 Байкальский институт природопользования Сибирского отделения Российской академии наук, \\ Россия, 670047, г. Улан-Удэ, ул. Сахьяновой, 6. \\ 2 Геологический институт Сибирского отделения Российской академии наук, \\ Россия, 670047, г. Улан-Удэ, ул. Сахьяновой, 6а.
}

\begin{abstract}
Актуальность. В последние годы наблюдается повышенный интерес к нефриту. Спрос на него требует разработки новых месторождений. Однако более 70 \% добытого нефритсодержащего сырья является некондиционным, невостребованным, оказывающим отрицательное воздействие на разные сфреры жизни. Кроме того, происходит расхищение некондиционного нефрита и вовлечение его в незаконный оборот. В связи с чем использование его в производстве различных видов продукции является актуальной задачей не только с экологической, но и с технологической стороны.
\end{abstract}

Цель: установить возможность использования некондиционного нефритсодержащего сырья в производстве строительных материалов.

Объекты: нефритсодержащие породы Улан-Ходинского месторождения Восточного Саяна.

Методы: химический, гранулометрический, механический методы анализа.

Результаты. Дана характеристика Улан-Ходинского месторождения Восточного Саяна. Изучены некондиционные породы, образуемые в результате добычи и выделения ценных фрракций из нефритсодержащего сырья. Установлено, что щебень из них имеет высокое качество. Он относится к Первой группе щебня, устойчив против всех видов распадов и стойкий к воздействию окружающей среды. Песок из отсевов дробления некондиционного нефрита является крупным песком с зернами уәловатой формы, обеспечивающей качество получаемых материалов. Определен модуль кислотности породы равный 1,59; модуль основности - 0,63; силикатный модуль - 12,66; а коэффрициент качества - 0,66. По своим показателям некондиционный нефрит имеет высокое качество и может использоваться в производстве строительных материалов. Однако установлено, что он не обладает возможностью твердеть самостоятельно, но способен выступать в роли гидравлической добавки в составе композиционных материалов. Получены цементные вяжущие композиции с добавкой некондиционного нефрритсодержащего сырья, изучены их фризико-механические свойства. Установлено, что прочность материалов зависит от количества добавки и времени измельчения сырьевой смеси. Определены технологические параметры получения тяжелых бетонов с использованием нефрита.

Выводы. Таким образом, некондиционный нефрит представляет собой перспективный сырьевой материал для получения новых видов строительных материалов. Вовлечение его в производственный оборот позволит извлекать дополнительную прибыль при переработке нефритсодержащего сырья, а также минимизировать негативное воздействие добывающих предприятий на окружающую природную среду. Кроме того, утилизация некондиционного нефрита предотвратит его расхищение и вовлечение в незаконный оборот нефрита.

\section{Ключевые слова:}

Отходы горнодобывающей промышленности, некондиционный нефрит, щебень, строительные материалы, предел прочности при сжатии.

\section{Введение}

В последние годы в мире наблюдается спрос на изделия из ювелирно-поделочных камней, в том числе нефрита. Это высоколиквидный камень, издавна используемый человеком, особо популярный в Китае и некоторых других странах. Наиболее ценится просвечивающий белый нефрит и шпинатно-зеленый с минимальным количеством рудных минералов.

Месторождения нефрита по генезису подразделяются на два эндогенных геолого-промышленных типа: апоультрамафитовый (метасоматиты по серпентинитам) и апокарбонатный (в тремолит-кальцитовых скарнах по доломитам). При этом ряд исследователей придерживаются мнения о ведущей роли динамометаморфизма в формировании нефритов. Апосерпентинитовый нефрит преимущественного зеленого цвета, а апокарбонатный светлоокрашенный. Экзогенная формация россыпей, как правило, аллювиальных, приурочена к коренным источниками.

Месторождения нефрита в России в основном находятся на юге Восточной Сибири и в Забайкалье: Западный и Восточный Саяны, западная часть хребта Хамар-Дабан и среднее течение Витима. В России на 1 января 2018 г. балансом были учтены 23 месторож- 
дения, в том числе Академическое в Челябинской области, Куртушибинское (участок Центральный) и Кантегирское в Красноярском крае, Куртушибинское (участок Восточный) в Республике Тыва, Онотское в Иркутской области, Удоканское (залежь 1) в Забайкальском крае. Из 17 месторождений Бурятии лидируют по количеству и качеству добываемого нефрита Оспинское и Кавоктинское.

Как известно, спрос на минеральные ресурсы сопровождается увеличением объема их добычи. Россия, наряду с Канадой и Китаем, входит в тройку стран мира - лидеров по производству нефрита. Почти все балансовые запасы нефрита России (100\% по $\mathrm{C}_{1} ; 93 \%$ нефрита-сырца и $91 \%$ сортового по $\mathrm{C}_{1}+\mathrm{C}_{2}$ на 1 января 2018 г.) сосредоточены в Бурятии. В 2017 г. на 8 месторождениях Республики по официальным данным было добыто 1332370 кг нефрита-сырца и 351260 кг сортового нефрита, а в Иркутской области - 120 кг сортового нефрита. В других регионах в 2017 г. добыча не велась. Таким образом, основная часть запасов и практически вся добыча нефритов сконцентрированы в Бурятии. Повышенный интерес к данному камню требует разработки новых месторождений.

Как известно, процесс добычи сопровождается образованием огромного количества вскрышных и вмещающих пород. Формируя отвалы, они негативно влияют на окружающую природную среду. Изъятие земель из оборота, пыление, выщелачивание вредных компонентов - основное воздействие отвалов, приводящее к деградации земель, загрязнению всех компонентов природной среды и ухудшению здоровья людей, проживающих на прилегающих территориях [1-3]. Кроме того, более 70 \% добытого нефритсодержащего сырья является некондиционным, невостребованным, оказывающим отрицательное воздействие на разные сферы жизни.

Все это требует от руководства добывающих предприятий переосмыслить свое отношение к горным отходам и научиться эффективно управлять ими $[4,5]$, в т. ч. вовлекая в производственный оборот с получением дополнительной продукции. Кроме того, утилизация некондиционного нефрита предотвратит его расхищение и вовлечение в незаконный оборот.

Основной отраслью, использующей отходы горнодобывающих предприятий, является строительная, для которой они выступают в роли высококачественных сырьевых материалов. Отвальные породы, образуемые при разработке месторождений нефрита, не составляют исключения. В их числе находится огромное количество серпентинитов, которые можно применять в различных направлениях производства строительных материалов [6, 7].

Серпентиниты обладают хорошей полирующей способностью и привлекательной окраской, что позволяет использовать их в качестве декоративного материала [6]. Они способны участвовать в процессах карбонизации за счет поглощения углекислого газа, выделяемого электростанциями, доменными печами, печами обжига извести [8-10]. Это качество учитывается и при получении магнезиального цемента, где серпентиниты выступают в роли основного сырьево- го материала [11]. А наличие в структуре серпентинитов высокого содержания химически связанной воды позволяет использовать их в качестве заполнителей при получении высокоплотных бетонов для защитных конструкций, ослабляющих поток нейтронов $[12,13]$. Эксплуатационные характеристики этих бетонов зависят от минерального состава и строения серпентинитов [14]. Однако использование данного сырья в производстве тяжелого бетона, по мнению [15], оказывает негативное влияние на качество конечного продукта. Но мелкозернистые бетоны можно модифицировать нанодисперсной добавкой серпентинита [16]. При этом повышается механическая прочность образцов, а также снижается их водопоглощение. Кроме того, серпентиниты могут применяться при получении керамических и огнеупорных материалов $[17,18]$. Данные породы можно использовать в качестве компонента связующего при пеллетировании железной руды для сталеплавильного производства [19]. Они являются перспективным сырьем для получения минеральных удобрений $[20,21]$. Из них выделяют ценные компоненты, в т. ч. магний [22-25]. Таким образом, серпентиниты, являющиеся вмещающими породами для нефритов, представляют собой ценное сырье для получения материалов различного назначения.

Некондиционный нефрит, не соответствующий требованиям производства камнерезных изделий и облицовочного камня, можно использовать как банный камень, в каменном литье и как удобрение пролонгированного действия. Последний вариант актуален для почв с дефицитом кальция и магния, особенно в районах с преобладающим развитием гранитов, таких как Забайкалье. Однако он практически нигде не используется. В связи с чем проводимые исследования являются актуальными не только с экологической, но и с технологической стороны.

Целью работы является установление возможности использования некондиционного нефритсодержащего сырья в производстве строительных материалов.

\section{Объекты и методы исследования}

Для проведения исследования использованы некондиционные нефритсодержащие породы УланХодинского месторождения следующего химического состава, масс. \%: $\mathrm{SiO}_{2}-56,20 ; \mathrm{Al}_{2} \mathrm{O}_{3}-0,94 ; \mathrm{Fe}_{2} \mathrm{O}_{3}-$ 0,$21 ; \mathrm{FeO}-3,28 ; \mathrm{MgO}-22,37 ; \mathrm{CaO}-13,48 ; \mathrm{Na}_{2} \mathrm{O}-$ 0,$04 ; \mathrm{K}_{2} \mathrm{O}-0,03 ;$ п.П.П. $-3,41$.

В ходе выполнения работы проведены химический, гранулометрический анализы. Химический анализ выполнялся посредством фотометрического, титриметрического, гравиметрического, атомноадсорбционного методов на спектрофотометре Юнико 1201 и атомно-абсорбционном спектрофотометре SOLAAR с соответствующим программным обеспечением.

Физико-механические показатели определяли по ГОСТ 310.4-76 «Цементы. Методы определения предела прочности при изгибе и сжатии» и ГОСТ 101802012 Бетоны. Методы определения прочности по контрольным образцам. 


\section{Результаты исследования и обсуждение}

Улан-Ходинское месторождение апоультрамафитового нефрита находится в юго-восточной части Восточного Саяна (Окинский район Республики Бурятия), на юго-востоке Холбын-Хаирханского ультрамафитового массива [26], в 1,5 км от горы УланХода. Месторождение сложено в основном серпентинитами. Интенсивное развитие разломов северозападного и северо-восточного простирания разобщило массив на отдельные блоки. Нефритоносная зона обнаружена в северо-западном и северовосточном контактах Холбын-Хаирханского гипербазитового массива. Вмещающие тела нефритов - серпентиниты - трещиноваты до полной раздробленности из-за интенсивного развития разрывных нарушений различного направления, что подтверждается геофизическими исследованиями. Предполагается, что нефриты сформированы в результате инфильтрационно-диффузионного кальциевого метасоматоза по антигоритовым спутанно-волокнистым серпентинитам на контакте с апогаббровыми, апогранитными метасоматитами [27]. В связи с тектонизированностью серпентинитов для жил нефрита характерно развитие трещиноватых, рассланцованных разностей табачнозеленого цвета вдоль контактов. Кондиционный нефрит светло-молочно-зеленого оттенка слагает только центральную часть жил. В связи с этим максимальный выход сортового нефрита составляет 20-25\%.

Для установления возможности использования некондиционного нефрита в производстве строительных материалов были изучены его основные физикохимические и механические свойства. Ситовой анализ исследуемых пород представлен в табл. 1 .

Как видно из полученных данных, более $50 \%$ щебня имеют размеры менее 15 мм, при котором на сите остается наибольшее количество породы (свыше $30 \%)$.

Определены физико-механические свойства щебня (табл. 2), которые соотнесены с требованиями ГОСТ 8267-93 «Щебень и гравий из плотных горных пород для строительных работ. Технические условия».

Таблица 1. Зерновой состав щеебня из некондиционного нефрита

Table 1. Grain composition of gravel from substandard nephrite

\begin{tabular}{|c|c|c|c|c|}
\hline \multirow[t]{2}{*}{$\begin{array}{c}\text { Размер } \\
\text { сит, мм } \\
\text { Sieve } \\
\text { size, } \\
\text { mm }\end{array}$} & $\begin{array}{c}\text { Частные } \\
\text { остатки } \\
\text { Partial } \\
\text { residuals }\end{array}$ & $\begin{array}{c}\text { Полные } \\
\text { остатки } \\
\text { Full } \\
\text { residuals } \\
\end{array}$ & $\begin{array}{c}\text { Полные } \\
\text { проходы } \\
\text { Full conduit }\end{array}$ & \multirow[t]{2}{*}{$\begin{array}{c}\text { Требования } \\
\text { ГОСТ 8267-93 } \\
\text { Requirements of } \\
\text { State standard } \\
\text { (GOST) } 8267-93\end{array}$} \\
\hline & \multicolumn{3}{|c|}{$\%$} & \\
\hline 20 & 9,6 & 9,6 & 90,4 & $\begin{array}{l}\mathrm{D} \text { до } 10 \\
\mathrm{D} \text { tо } 10\end{array}$ \\
\hline 15 & 39,2 & 48,8 & 51,2 & - \\
\hline 12,5 & 25,6 & 74,4 & 25,6 & $0,5(\mathrm{D}+\mathrm{d}) 30 \div 80$ \\
\hline 10 & 18,1 & 92,5 & 7,5 & - \\
\hline 5 & 5,8 & 98,3 & 1,7 & $\begin{array}{c}\mathrm{d} \text { от } 90 \text { до } 100 \\
\mathrm{~d} \text { from } 90 \text { to } 100\end{array}$ \\
\hline$<$ & 1,7 & 100,0 & 0,0 & \\
\hline
\end{tabular}

Установлено, что исследуемый материал имеет высокое качество. Он относится к Первой группе щебня, для которой регламентировано содержание зерен пластинчатой и игловатой формы не более 15 мас. \%. Он противостоит всем видам распадов, а также устойчив к воздействию окружающей среды. Вторичные изменения на нефрите проявляются в течение 4-6 тыс. лет [28], поэтому в ходе эксплуатации изделий он не будет подвергаться выщелачиванию. Щебень из некондиционного нефрита можно использовать для получения тяжелых бетонов и выполнения различных видов строительных работ.

Таблица 2. Физико-механические показатели щебня из некондииионного нефрита

Table 2. Physical and mechanical parameters of gravel from substandard nephrite

\begin{tabular}{|c|c|c|}
\hline $\begin{array}{c}\text { Показатели } \\
\text { Indicators }\end{array}$ & $\begin{array}{c}\text { Некондици- } \\
\text { онный } \\
\text { нефрит } \\
\text { Substandard } \\
\text { nephrite } \\
\end{array}$ & $\begin{array}{c}\text { Требования } \\
\text { ГОСТ 8267-93 } \\
\text { Requirements of } \\
\text { State standard } \\
\text { (GOST) 8267-93 }\end{array}$ \\
\hline $\begin{array}{l}\text { Содержание пылевидных и } \\
\text { глинистых частиц, масс. \% } \\
\text { Content of dust and clay } \\
\text { particles, wt. \% }\end{array}$ & 0,4 & $\begin{array}{c}\text { не более } 1 \\
\text { no more than } 1\end{array}$ \\
\hline $\begin{array}{l}\text { Содержание глины в ком- } \\
\text { ках, мacc. \% } \\
\text { Content of clay in lumps, } \\
\text { wt. \% }\end{array}$ & $\begin{array}{c}\text { нет } \\
\text { no }\end{array}$ & $\begin{array}{c}\text { не более } 0,25 \\
\text { no more than } 0,25\end{array}$ \\
\hline $\begin{array}{l}\text { Содержание зерен пластин- } \\
\text { чатой (лещадной) и игловой } \\
\text { формы, масс. \% } \\
\text { Content of grains of lamellar } \\
\text { (flaky) and needle-shaped } \\
\text { form, wt. \% }\end{array}$ & 10,3 & $\begin{array}{c}\text { не более } 15 \\
\text { no more than } 15\end{array}$ \\
\hline $\begin{array}{l}\text { Содержание зерен слабых } \\
\text { пород, масс. \% } \\
\text { Content of grains of weak } \\
\text { rocks, wt. \% }\end{array}$ & $\begin{array}{c}\text { нет } \\
\text { no }\end{array}$ & $\begin{array}{c}\text { не более } 5 \\
\text { no more than } 5\end{array}$ \\
\hline $\begin{array}{l}\text { Марка по дробимости } \\
\text { Tyре on crushability }\end{array}$ & $\begin{array}{l}\text { M } 1400 \\
\text { M } 1400 \\
\end{array}$ & - \\
\hline $\begin{array}{l}\text { Марка по истираемости } \\
\text { Туре on abradability }\end{array}$ & $\begin{array}{c}\text { И } 2 \\
\text { I } 2 \\
\end{array}$ & - \\
\hline $\begin{array}{l}\text { Морозостойкость } \\
\text { Frost resistance }\end{array}$ & $\begin{array}{l}\text { F } 150 \\
\text { F } 150 \\
\end{array}$ & - \\
\hline
\end{tabular}

Известно, что в процессе дробления горных пород образуются отсевы, которые можно использовать в качестве мелкого заполнителя для бетонов. Поэтому были изучены свойства отсевов дробления исследуемых пород, соотнесенные с требованиями ГОСТ 31424-2010 «Материалы строительные нерудные из отсевов дробления плотных горных пород при производстве щебня. Технические условия». Данные ситового анализа показаны в табл. 3.

Песок из отсевов дробления некондиционного нефрита относится к группе крупных песков, более 70 \% которого имеют размеры частиц, превышающие 0,315 мм. Насыпная плотность отсевов дробления составляет $1820 \mathrm{\kappa} / \mathrm{M}^{3}$, истинная плотность $-2964 \mathrm{\kappa г} / \mathrm{M}^{3}$. Они содержат пылевидные и глинистые частицы в количестве 2,3 \% и не содержат глины в комках. Зерна их имеют угловатую форму, позволяющую обеспечивать качество получаемых материалов. По своему качеству песок из отсевов дробления соответствует требованиям государственного стандарта, предъявляемым к данному сырью, и пригоден для использования в качестве мелкого заполнителя в бетонах. 
Таблица 3. Зерновой состав отсевов дробления некондичионного нефрита

Table 3. Grain structure of the crushing screenings of substandard nephrite

\begin{tabular}{|c|c|c|c|c|}
\hline \multirow{2}{*}{$\begin{array}{c}\text { Размер } \\
\text { сит, мм } \\
\begin{array}{c}\text { Sieve } \\
\text { size, mm }\end{array}\end{array}$} & $\begin{array}{c}\text { Частные } \\
\text { остатки } \\
\text { Partial } \\
\text { residuals }\end{array}$ & $\begin{array}{c}\text { Полные } \\
\text { остатки } \\
\text { Full } \\
\text { residuals }\end{array}$ & $\begin{array}{c}\text { Полные } \\
\text { проходы } \\
\text { Full } \\
\text { conduit }\end{array}$ & $\begin{array}{c}\text { Требования } \\
\text { ГОСТ 31424-2010 } \\
\text { Requirements of } \\
\text { State standard } \\
\text { (GOST) 31424-2010 }\end{array}$ \\
\hline 2,5 & 16,3 & 16,3 & 83,7 & - \\
\hline 1,25 & 16,0 & 32,3 & 67,7 & - \\
\hline 0,63 & 22,2 & 54,5 & 45,5 & $45-65$ \\
\hline 0,315 & 23,5 & 78,0 & 22,0 & - \\
\hline 0,16 & 12,5 & 90,2 & 9,8 & $\begin{array}{c}\text { не болеe 15 } \\
\text { nо mоге 15 }\end{array}$ \\
\hline 0,071 & 6,9 & 97,4 & 2.9 & - \\
\hline$<$ & 2,6 & 100,0 & 0,0 & - \\
\hline
\end{tabular}

Для установления возможности использования некондиционного нефрита в производстве строительных материалов были определены показатели породы, важные в данной сфере. В результате проведенных исследований установлено, что модуль кислотности нефрита составляет 1,59 ; модуль основности (гидравлический модуль) - 0,63; силикатный (кремнеземистый) модуль - 12,66; а коэффициент качества (гидравлическая активность) - 0,66. По своим показателям исследуемая порода относится к кислым и скрыто активным и может использоваться в керамической промышленности, дорожном строительстве. Она не обладает возможностью твердеть самостоятельно, поэтому способна выступать в роли гидравлической добавки в составе композиционных вяжущих материалов.

Было изучено влияние количества добавки нефрита к портландцементному клинкеру и времени измельчения сырьевой смеси на механические показатели полученных материалов. В качестве помольного агрегата используют различные виды активаторов: дезинтеграторы, планетарные, вибрационные, шаровые, виброшаровые, вертикальные валковые мельницы и др. [29-31]. В нашем случае использовался стержневой вибрационный измельчитель марки 75Т-ДрМ. Продолжительность процесса варьировалась от 5 до 20 минут. Количество добавки не превышало $40 \%$. Образцы твердели в течение 28 суток при температуре $(20 \pm 2){ }^{\circ} \mathrm{C}$ и влажности $(95 \pm 5) \%$. По окончании определялась прочность при сжатии.

Установлено, что исследуемые параметры оказывают влияние на прочность композиционных вяжущих материалов (рис. 1).

Как видно из представленных данных, большую прочность имеют вяжущие с $30 \%$ добавки отходов. Увеличение ее до $40 \%$ приводит к значительному снижению прочностных показателей вяжущих материалов. Максимальные значения наблюдаются при 10 минутах измельчения сырьевых смесей для композиционных материалов и 5 минутах измельчения для портландцемента. Необходимо отметить, что у последнего происходит резкое снижение прочности к 10 минутам помола, после чего данный процесс замедляется.

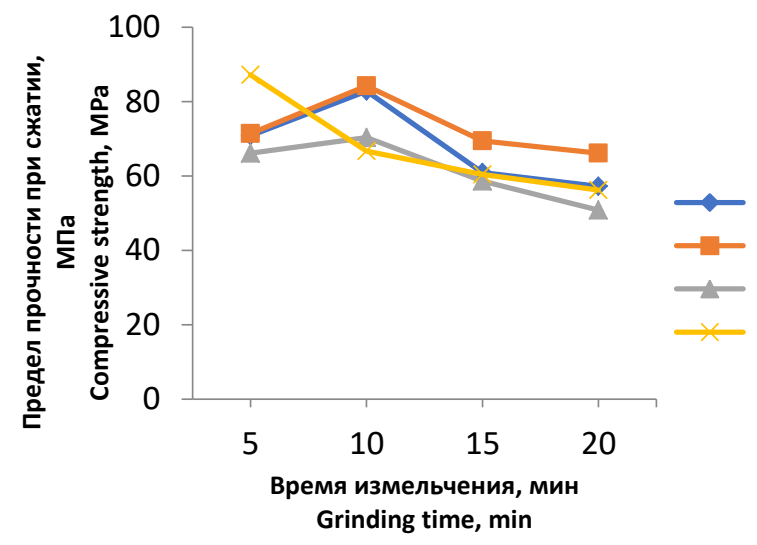

Pис. 1. Зависимость прочности композиционных вяжущчих материалов от времени измельчения сырьевой смеси и добавки некондиционного нефрита в количестве, масс. \%: 1 - 20; 2 - 30; 3-40; 4 -0

Fig. 1. Dependence of the strength of composite binders on grinding time of raw mixture and addition of substandard nephrite in the amount of, wt. \%: $1-20$; $2-30 ; 3-40 ; 4-0$

Изучены физико-механические свойства полученных материалов, которые представлены в табл. 4 .

Таблица 4. Физико-механические свойства композиционных вяжущчих материалов

Table 4. Physical and mechanical properties of composite binders

\begin{tabular}{|c|c|c|}
\hline $\begin{array}{c}\text { Показатели } \\
\text { Indicators }\end{array}$ & $\begin{array}{c}\text { Портландце- } \\
\text { мент М400Д0 } \\
\text { Portland } \\
\text { cement } \\
\text { M400D0 } \\
\end{array}$ & $\begin{array}{c}\text { Цемент с добав- } \\
\text { кой нефрита } \\
\text { Cement with } \\
\text { nephrite addition }\end{array}$ \\
\hline $\begin{array}{l}\text { Начало схватывания } \\
\text { Beginning of stiffening }\end{array}$ & $\begin{array}{l}3 \text { ч } 20 \text { мин } \\
3 \text { h } 20 \text { min }\end{array}$ & $\begin{array}{l}4 \text { ч } 51 \text { мин } \\
4 \text { h } 51 \mathrm{~min} \\
\end{array}$ \\
\hline $\begin{array}{l}\text { Конец схватывания } \\
\text { End of stiffening }\end{array}$ & $\begin{array}{l}5 \text { ч } 20 \text { мин } \\
5 \text { h } 20 \text { min }\end{array}$ & $\begin{array}{l}7 \text { ч } 45 \text { мин } \\
7 \text { h } 45 \text { min }\end{array}$ \\
\hline $\begin{array}{l}\text { Расплыв конуса } \\
\text { Come flow diameter }\end{array}$ & 114,0 & 117,0 \\
\hline 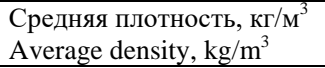 & 2315,0 & 2256,0 \\
\hline $\begin{array}{l}\text { Предел прочности при } \\
\text { сжатии, МПа } \\
\text { Compressive strength, MPa }\end{array}$ & 66,7 & 84,2 \\
\hline
\end{tabular}

Композиционные вяжущие материалы с добавкой некондиционного нефрита имеют более продолжительный период твердения. У них он составляет 2 часа 54 минуты, в то время как у портландцемента время схватывания 2 часа. При меньшей средней плотности они обладают повышенными прочностными показателями.

В целом по своим физико-механическим показателям полученные композиционные материалы удовлетворяют требованиям ГОСТ 10178-85 «Портландцемент и шлакопортландцемент. Технические условия» и могут применяться в строительстве.

Пригодность щебня из некондиционного нефрита для использования в производстве строительных материалов обусловливает проведение исследований по получению из него тяжелых бетонов. При этом в качестве сырьевых материалов во всех образцах ис- 
пользовались кварцевый песок (мелкий заполнитель) и портландцемент М400ДО Тимлюйского цементного завода (вяжущий материал). Объектом сравнения являлись бетоны на гранитном щебне, а также на песчано-гравийной смеси (ПГС). Были изготовлены образцы - кубы размером $5 \times 5 \times 5$ см при наибольшей крупности зерен заполнителя 10 мм, которые испытывались на сжатие. Водоцементное отношение В/Ц составляло 0,55; подвижность бетонных смесей - 1-4 см.

В процессе выполнения работы изучалось, как вид крупного заполнителя влияет на прочностные характеристики бетонов. Данные фиксировались в возрасте 7 и 28 суток стандартного твердения. Полученные значения свидетельствуют, что бетоны с использованием некондиционного нефрита обладают лучшими показателями, а худшими - с гравийно-песчаной смесью. Установлено, что к 7 суткам нормальновлажностного твердения образцы с добавкой некондиционного нефрита набирают около 79 \% марочной прочности, в то время как у стандартного образца этот показатель достигает $72 \%$.

Была определена плотность полученных материалов, т. к. от данного показателя зависит область их применения. Она уменьшается в зависимости от вида крупного заполнителя в ряду нефрит $\rightarrow$ гранит $\rightarrow$ ППС и имее следующие показатели 2462 $\kappa г / \mathrm{M}^{3} \rightarrow 2387 \mathrm{\kappa} / \mathrm{M}^{3} \rightarrow 2340 \mathrm{\kappa} / \mathrm{M}^{3}$. Средняя плотность

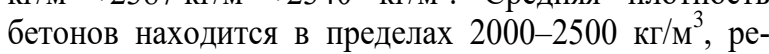
гламентируемых для тяжелых бетонов. Это позволяет использовать их во всех несущих конструкциях.
Установлены технологические параметры получения тяжелых бетонов из некондиционного нефрита. Оптимальным является следующий состав основных компонентов, \% по массе: портландцемент - 18,9; кварцевый песок - 28,3; щебень - 42,5; вода - 10,3. Водоцементное отношение В/Ц составляет 0,55. Процесс формования образцов осуществляется посредством вибрирования в течение 20 секунд. Твердение продолжительностью 28 суток происходит в нормально-влажностных условиях при температуре $(20 \pm 2){ }^{\circ} \mathrm{C}$ и относительной влажности воздуха $(95 \pm 5) \%$. Разработанные бетонные смеси пригодны для изготовления фундаментных блоков и внутренних стеновых панелей.

В целом в результате проведенных исследований разработаны технологические решения получения новых видов композиционных вяжущих материалов и тяжелых бетонов из некондиционного нефрита (рис. 2)

Необходимо отметить, что отсевы, образуемые от дробления изучаемых пород, являются перспективным заменителем природного песка в технологическом цикле производства бетона. Они представляют собой частицы неправильной формы с острыми гранями, позволяющими заполнять пустоты между зернами крупного заполнителя и формировать прочную структуру, обуславливающую улучшение физико-механических характеристик получаемых материалов.

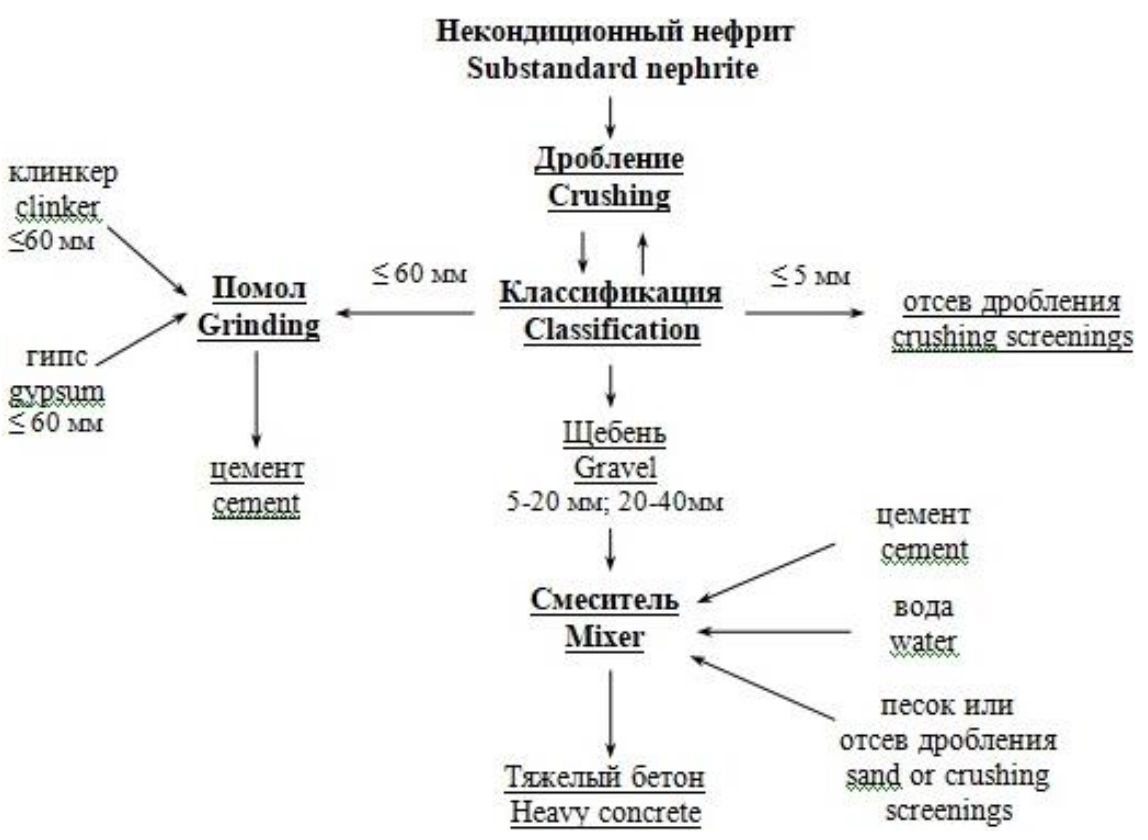

Рис. 2. Приниипиальная технологическая схема переработки некондиционного нефритсодержащего сырья

Fig. 2. Basic technological scheme of processing of substandard nephrite

Помимо указанных направлений, некондиционный нефрит может применяться в производстве асфальтобетонных смесей и др. Крошка из данных пород может использоваться при изготовлении декоративных бетонных изделий, а также в качестве декора при отделке фасадов зданий и интерьера помещений.

\section{Заключение}

Таким образом, в результате проведенных исследований определен химический, гранулометрический составы некондиционных нефритов Улан-Ходинского месторождения Восточного Саяна. Изучены их физико-химические и технологические свойства. Установ- 
лено, что щебень из них имеет высокую марку по дробимости, устойчив ко всем видам распадов и стойкий к воздействию окружающей среды. Песок из отсевов дробления относится к группе крупных песков с угловатой формой зерен. Определены основные показатели пород: модуль основности, кислотности, силикатный модуль, гидравлическая активность. Установлено, что некондиционные нефриты могут быть использованы при производстве строительных материалов.

Получены композиционные вяжущие материалы с добавкой некондиционного нефритсодержащего сырья, изучены их физико-механические свойства. Установлено, что прочность композиционных вяжущих материалов зависит от количества добавки и времени измельчения сырьевой смеси. Оптимальными технологическими параметрами являются: время измельчения сырьевой смеси - 10 минут, количество добавки - 30 \%. По своим физико-механическим показателям композиционные материалы удовлетворяют требованиям ГОСТ 10178-85 и могут применяться в строительстве.

Определены технологические параметры получения тяжелых бетонов из некондиционного нефрита.

\section{СПИСОК ЛИТЕРАТУРЬ}

1. Emmanuel A.Y., Jerry C.S., Dzigbodi D.A. Review of environmental and health impacts of mining in Ghana // Journal of Health and Pollution. - 2018. - V. 8. - № 17. - P. 43-52.

2. Jain M.K., Das A. Impact of mine waste leachates on aquatic environment: a review // Current Pollution Reports. - 2017. - V. 3. P. 31-37. DOI: $10.1007 / \mathrm{s} 40726-017-0050-\mathrm{z}$

3. Wellen C., Shatilla N.J., Carey S.K. The influence of mining on hydrology and solute transport in the Elk Valley, British Columbia Canada // Environmental Research Letters. - 2018. - V. 13. 074012. DOI: $10.1088 / 1748-9326 /$ aaca9d

4. Re-thinking mining waste through an integrative approach led by circular economy aspirations / M. Tayebi-Khorami, M. Edraki, G. Corder, A. Golev // Minerals. - 2019. - V. 9. - № 5. - P. 286. DOI: $10.3390 / \min 9050286$

5. Carvalho F.P. Mining industry and sustainable development: time for Change // Food and Energy Security. - 2017. - V. 6. - № 2. P. 61-77. DOI: $10.1002 /$ fes 3.109

6. Barman S.K., Tiwari S.K. Serpentinites: a byproduct of ophiolite quarries for regional development: a case study of South Andaman Island, Bay of Bengal // International Journal of Multidisciplinary Research and Development. - 2016. - V. 3. - Iss. 9. - P. 190-196.

7. Serpentinites: mineral structure, properties and technologica applications / O.R.D.R. Carmignano, S.S. Vieira, P.R.G. Brandão, A.C. Bertoli, R.M. Lago // Journal of the Brazilian Chemical Society. - 2020. - V. 31. - № 1. - P. 2-14. DOI: 10.21577/01035053.20190215

8. Serpentinite carbonation process routes using ammonium sulfate and integration in industry / R. Zevenhoven, M. Slotte, E. Koivisto, R. Erlund // Energy Technology. - 2017. - V. 5. - P. 945-954. DOI: $10.1002 /$ ente.201600702

9. Insights into the dissolution kinetics of thermally activated serpentine for $\mathrm{CO} 2$ sequestration / F. Farhang, M. Rayson, G. Brent, T. Hodgins, M. Stockenhuber, E. Kennedy // Chemical Engineering Journal. - 2017. - V. - 330. - P. 1174-1186.

10. Reaction mechanism for the aqueous-phase mineral carbonation of heat-activated serpentine at low temperatures and pressures in flue gas conditions / L.C. Pasquier, G. Mercier, J.F. Blais, E. Cecchi, S. Kentish // Environmental Science and Technology. - 2014. V. 48. - № 9. - P. 5163-5170. DOI: 10.1021/es405449v

11. Lee J.-K., Soh J.-S. Performance of magnesia cement using $\mathrm{MgCO} 3$ and serpentine // Journal of the Korean Ceramic Society. 2016. - V. 53. - № $1 . \quad$ - P. 116-121. DOI: 10.4191/kcers.2016.53.1.116
Оптимальным является следующий состав основных компонентов, \% по массе: портландцемент - 18,9; кварцевый песок - 28,3; щебень - 42,5; вода - 10,3. Водоцементное отношение В/Ц составляет 0,55. Образцы формуются вибрированием продолжительностью 20 секунд и твердеют в течение 28 суток при температуре $(20 \pm 2){ }^{\circ} \mathrm{C}$ и относительной влажности воздуха $(95 \pm 5) \%$. Разработанные бетонные смеси пригодны для производства фундаментных блоков и внутренних стеновых панелей.

Таким образом, некондиционный нефрит перспективен для получения различных видов строительных материалов. Вовлечение его в производственный оборот позволит извлекать дополнительную прибыль при переработке нефритсодержащего сырья, а также минимизировать негативное воздействие добывающих предприятий на окружающую природную среду. Кроме того, утилизация некондиционного нефрита предотвратит его расхищение и вовлечение в незаконный оборот нефрита.

Работа выполнена в рамках государственных заданий БИП СО РАН, № АААА-А17-117021310253-8 и ГИН СО PAH, № AAAA-A17-117011650012-7

12. Ouda A.S. Development of high-performance heavy density concrete using different aggregates for gamma-ray shielding / Progress in Nuclear Energy. - 2015. - V. 79. - P. 48-55.

13. Trace elements with large activation cross section in concrete materials in Japan / A. Suzuki, T. Iida, J. Moriizumi, Y. Sakuma, J. Takada, K. Yamasaki, T. Yoshimoto // Journal of Nuclear Science and Technology. - 2001. - V. 38. - № 7. - P. 542-550. DOI: $10.1080 / 18811248.2001 .9715065$

14. Denisov A. Radiation changes in serpentinite concretes of «dry» radiation shield in nuclear power plants // IOP Conference Series: Materials Science and Engineering. - 2018. - V. 365. - 032028. DOI: $10.1088 / 1757-899 \mathrm{X} / 365 / 3 / 032028$

15. The influence of alteration of aggregates on the quality of the concrete: a case study from serpentinites and andesites from Central Macedonia (North Greece) / P. Petrounias, P.P. Giannakopoulou, A. Rogkala, P.M. Stamatis, B. Tsikouras, D. Papoulis, P. Lampropoulou, K. Hatzipanagiotou // Geosciences. 2018. - V. 8. - № 4. - P. 115. DOI: 10.3390/geosciences 8040115

16. Пустовгар А.П., Лукутцова Н.П., Устинов А.Г. Изучение свойств мелкозернистого бетона, модифицированного нанодисперсной добавкой серпентинита // Вестник МГСУ. 2013. - № 3 - C. 155-162.

17. Nemat S., Ramezani A., Emami S.M. Possible use of waste serpentine from Abdasht chromite mines into the refractory and ceramic industries // Ceramics International. - 2016. - V. 42. Iss. 16. - P. 18479-18483. DOI: 10.1016/j.ceramint.2016.08.184

18. Nemat S., Ramezani A., Emami S.M. Recycling of waste serpentine for the production of forsterite refractories: the effects of various parameters on the sintering behavior // Journal of the Australian Ceramic Society. - 2019. - V. 55. - Iss. 2. - P. 425-431.

19. Carmignano O.R.D.R., Carvalho C.F. Comparison between bentonite and serpentinite in the production process of iron ore pellets // Metallurgy and materials. - 2014. - V. 67. - № 1. - P. 47-53.

20. Власенко В.П., Осипов А.В., Костенко В.В. Состав и свойства горной породы серпентинит и возможности использования ее в качестве мелиоранта почв // Агрохимический вестник. 2019. - № 4. - C. 28-31. DOI: 10.24411/0235-2516-2019-10054

21. Potential slow release fertilizers based on $\mathrm{K} 2 \mathrm{MgSiO} 4$ obtained from serpentinite / F.C. Ballotin, W.O. Santos, E.M. Mattiello, O. Carmignano, A.P.C. Teixeira, R.M. Lago // Journal of the Brazilian Chemical Society. - 2020. - V. 31. - № 4. - P. 653-661. DOI: $10.21577 / 0103-5053.20190229$

22. Передерин Ю.В., Усольцева И.О., Краснощекова Д.В. Основные технологии получения оксида магния из серпентинита // 
Ползуновский вестник. - 2019. - № 2. - С. 123-127. DOI: 10.25712/ASTU.2072-8921.2019.02.024

23. Preparation of crystalline $\mathrm{Mg}(\mathrm{OH}) 2$ nanopowder from serpentinite mineral / V. Sirota, V. Selemenev, M. Kovalevaa, I. Pavlenko, K. Mamunin, V. Dokalov, M. Yapryntsev // International Journal of Mining Science and Technology. - 2018. - V. 28. - Iss. 3. P. 499-503. DOI: $10.1016 /$ j.ijmst.2017.12.018

24. Feasibility study on the utilization of serpentine residues for $\mathrm{Mg}(\mathrm{OH}) 2$ production / C. Sierra, S. Chouinard, L.C. Pasquier, G. Mercier, J.F. Blais // Waste Biomass Valor. - 2018. - V. 9. P. 1921-1933. DOI: 10.1007/s12649-017-9926-9

25. Influence of physicochemical properties of Brazilian serpentinite on the leaching process for indirect $\mathrm{CO} 2$ mineral carbonation G.L.A.F. Arce, T.G.S. Neto, I. Ávila, C.M.R. Luna, J.C. dos Santos, J.A.C. Jr // Hydrometallurgy. - 2017. - V. 169. - P. 142-151. DOI 10.1016/j.hydromet.2017.01.003

26. Малышев А.В., Кислов Е.В. Петролого-геохимические аспекты Холбын-Хаирханского гипербазитового плутона (Восточный Саян) // Металлогения древних и современных океанов2017. Дифференциация и причины разнообразия рудных месторождений. Научное издание. - Миасс: ИМин УрО РАН, 2017. - C. $221-224$
27. Малышев А.В., Кислов Е.В. Геология Улан-Ходинского месторождения апоультрамафитового нефрита (юго-восточная часть Восточного Саяна) // Металлогения древних и современных океанов-2015. Месторождения океанических структур: геология, минералогия, геохимия и условия образования. Научное издание. - Миасс: ИМин УрО РАН, 2015. - С. 220-223.

28. Портнов А.М., Дронова Н.Д. Неповторимый нефрит // Природа. - 2016. - № 12. - С. 18-23.

29. Голик В.И., Комащенко В.И., Разоренов Ю.И. Активация компонентов твердеющих смесей при подземной добыче руд // Известия ТулГУ. Науки о Земле. - 2017. - Вып. 3. - С. 113-123.

30. Влияние способа измельчения на активность ингредиентов бетонной смеси / О.Н. Буренина, Н.Н. Давыдова, А.В. Андреева, М.Е. Саввинова // Научный журнал КубГАУ. - 2015. № 111 (07). URL: http://ej.kubagro.ru/2015/07/pdf/70.pdf (дата обращения 11.02.2020).

31. Исследование влияния активирования портландцемента на физико-механические свойства бетона / Приходов Д.А., Баранов В.Н., Никифорова Э.М., Гильманшина Т.Р. // Фундаментальные исследования. - 2016. - № 11. - С. 938-943.

Поступила 26.12.2019 2.

\section{Информация об авторах}

Худякова Л.И., доктор технических наук, старший научный сотрудник лаборатории химии и технологии природного сырья Байкальского института природопользования Сибирского отделения Российской академии наук. Kuслов E.B., кандидат геолого-минералогических наук, заведующий лабораторией геохимии и рудообразующих процессов Геологического института Сибирского отделения Российской академии наук.

Палеев П.Л., кандидат технических наук, научный сотрудник лаборатории химии и технологии природного сырья Байкальского института природопользования Сибирского отделения Российской академии наук.

Малышев A.B., инженер лаборатории геохимии и рудообразующих процессов Геологического института Сибирского отделения Российской академии наук. 
UDC 552.31:553

\title{
COMPREHENSIVE USE OF SUBSTANDARD NEPHRITE
}

\author{
Liudmila I. Khudyakova1, \\ lkhud@binm.ru
}

\section{Evgeniy V. Kislov²,} evg-kislov@yandex.ru

Pavel L. Paleev1, palpavel@mail.ru

\author{
Alexey V. Malyshev², \\ Waylander6@mail.ru \\ 1 Baikal Institute of Nature Management Siberian Branch of the Russian Academy of Sciences, \\ 6, Sakhyanov street, Ulan-Ude, 670047, Russia. \\ 2 Geological Institute Siberian Branch of the Russian Academy of Sciences, \\ 6a, Sakhyanova street, Ulan-Ude, 670047, Russia.
}

The relevance. In recent years, there has been an increased interest in nephrite. Demand for it requires the development of new fields. However, more than $70 \%$ of the extracted nephrite containing raw materials is of poor quality, unclaimed, having a negative impact on different spheres of life. In addition, there is a plunder of substandard nephrite and its involvement in illegal trafficking. In this regard, its use in production is an urgent task not only from the environmental but also from the technological side.

The main aim of the research is to establish the possibility of using substandard nephrite containing raw materials in production of building materials.

Objects: nephrite-containing rocks of Ulan-Khoda Deposit of Eastern Sayan.

Methods: chemical, granulometric, mechanical methods of analysis.

Results. The characteristic of Ulan-Khoda Deposit of Eastern Sayan is given. Substandard rocks formed as a result of extraction and separation of valuable fractions from nephrite containing raw materials were studied. It is established that break-stone from them has high quality. It belongs to the First group of gravel, resistant to all kinds of decay and to the environment. The sand from the crushing screenings of substandard nephrite is large sand with grains of angular shape, ensuring the quality of the obtained materials. The acidity modulus of the rock was determined to be 1,59; basicity modulus - 0,63; silicate modulus - 12,66; and quality factor - 0,66. According to its indicators, substandard nephrite is of high quality and can be used in production of building materials. However, it is established that it does not have the ability to harden on its own, but is able to act as a hydraulic additive in composite materials. Cement binding compositions with the addition of substandard nephrite containing raw materials were obtained, their physical and mechanical properties were studied. It is established that the strength of materials depends on the amount of additives and the grinding time of the raw mixture. The technological parameters of obtaining heavy concretes using nephrite were determined.

Summary. Thus, substandard nephrite is a promising raw material for production of new types of building materials. Its involvement in production turnover will allow extracting additional profit in processing nephrite-containing raw materials, as well as minimizing the negative impact of mining enterprises on the environment. In addition, the disposal of substandard nephrite prevents its plunder and involvement in the illegal trafficking.

\section{Key words:}

Mining waste, substandard nephrite, gravel, building materials, compressive strength.

The investigations were performed as part of state programs BINM SB RAS, no. AAAA-A17-117021310253-8 and GIN SB RAS, no. AAAA-A17-117011650012-7

\section{REFERENCES}

1. Emmanuel A.Y., Jerry C.S., Dzigbodi D.A. Review of environmental and health impacts of mining in Ghana. Journal of Health and Pollution, 2018, vol. 8, no. 17, pp. 43-52.

2. Jain M.K., Das A. Impact of mine waste leachates on aquatic environment: a review. Current Pollution Reports, 2017, vol. 3, pp. 31-37. DOI: 10.1007/s40726-017-0050-z

3. Wellen C., Shatilla N.J., Carey S.K. The influence of mining on hydrology and solute transport in the Elk Valley, British Columbia, Canada. Environmental Research Letters, 2018, vol. 13, 074012. DOI: 10.1088/1748-9326/aaca9d

4. Tayebi-Khorami M., Edraki M., Corder G., Golev A. Re-thinking mining waste through an integrative approach led by circular economy aspirations. Minerals, 2019, vol. 9, no. 5, pp. 286. DOI: $10.3390 / \min 9050286$
5. Carvalho F.P. Mining industry and sustainable development: time for Change. Food and Energy Security, 2017, vol. 6, no. 2. pp. 61-77. DOI: $10.1002 /$ fes 3.109

6. Barman S.K., Tiwari S.K. Serpentinites: a byproduct of ophiolite quarries for regional development: a case study of South Andaman Island, Bay of Bengal. International Journal of Multidisciplinary Research and Development, 2016, vol. 3, Iss. 9, pp. 190-196.

7. Carmignano O.R.D.R., Vieira S.S., Brandão P.R.G., Bertoli A.C., Lago R.M. Serpentinites: mineral structure, properties and technological applications. Journal of the Brazilian Chemical Society, 2020, vol. 31, no. 1, pp. 2-14. DOI: 10.21577/01035053.20190215

8. Zevenhoven R., Slotte M., Koivisto E., Erlund R. Serpentinite carbonation process routes using ammonium sulfate and integration in industry. Energy Technology, 2017, vol. 5, pp. 945 954. DOI: $10.1002 /$ ente.201600702 
9. Farhang F., Rayson M., Brent G., Hodgins T., Stockenhuber M. Kennedy E. Insights into the dissolution kinetics of thermally activated serpentine for $\mathrm{CO} 2$ sequestration. Chemical Engineering Journal, 2017, vol. 330, pp. 1174-1186.

10. Pasquier L.C., Mercier G., Blais J.F., Cecchi E., Kentish S. Reaction mechanism for the aqueous-phase mineral carbonation of heat-activated serpentine at low temperatures and pressures in flue gas conditions. Environmental Science and Technology, 2014, vol. 48, no. 9, pp. 5163-5170. DOI: 10.1021/es405449v

11. Lee J.-K., Soh J.-S. Performance of magnesia cement using $\mathrm{MgCO}_{3}$ and serpentine. Journal of the Korean Ceramic Society, 2016, vol. 53, no. 1 , pp. 116-121. DOI: 10.4191/kcers.2016.53.1.116

12. Ouda A.S. Development of high-performance heavy density concrete using different aggregates for gamma-ray shielding. Progress in Nuclear Energy, 2015, vol. 79, pp. 48-55.

13. Suzuki A., Iida T., Moriizumi J., Sakuma Y., Takada J., Yamasaki K., Yoshimoto T. Trace elements with large activation cross section in concrete materials in Japan. Journal of Nuclear Science and Technology, 2001, vol. 38, no. 7, pp. 542-550. DOI: 10.1080/18811248.2001.9715065

14. Denisov A. Radiation changes in serpentinite concretes of «dry» radiation shield in nuclear power plants. IOP Conference Series: Materials Science and Engineering, 2018, vol. 365, 032028. DOI: 10.1088/1757-899X/365/3/032028

15. Petrounias P., Giannakopoulou P.P., Rogkala A., Stamatis P.M., Tsikouras B., Papoulis D., Lampropoulou P., Hatzipanagiotou K. The influence of alteration of aggregates on the quality of the concrete: a case study from serpentinites and andesites from Central Macedonia (North Greece). Geosciences, 2018, vol. 8, no. 4, pp. 115. DOI: 10.3390/geosciences8040115

16. Pustovgar A.P., Lukuttsova N.P., Ustinov A.G. Study of the properties of fine-grained concrete modified by the nanodisperse serpentinite additive. Proceedings of Moscow State University of Civil Engineering, 2013, no. 3, pp. 155-162. In Rus.

17. Nemat S., Ramezani A., Emami S.M. Possible use of waste serpentine from Abdasht chromite mines into the refractory and ceramic industries. Ceramics International, 2016, vol. 42, Iss. 16, pp. 18479-18483. DOI: 10.1016/j.ceramint.2016.08.184

18. Nemat S., Ramezani A., Emami S.M. Recycling of waste serpentine for the production of forsterite refractories: the effects of various parameters on the sintering behavior. Journal of the Australian Ceramic Society, 2019, vol. 55, Iss. 2, pp. 425-431.

19. Carmignano O.R.D.R., Carvalho C.F. Comparison between bentonite and serpentinite in the production process of iron ore pellets. Metallurgy and materials, 2014, vol. 67, no. 1, pp. 47-53.

20. Vlasenko V.P., Osipov A.V., Kostenko V.V. The composition and properties of the serpentinite rock and the possibility of using it as a meliorant of soils. Agrochemical Herald, 2019, no. 4, pp. 28-31. DOI: 10.24411/0235-2516-2019-10054 In Rus.

21. Ballotin F.C., Santos W.O., Mattiello E.M., Carmignano O., Teixeira A.P.C., Lago R.M. Potential slow release fertilizers based on $\mathrm{K}_{2} \mathrm{MgSiO}_{4}$ obtained from serpentinite. Journal of the Brazilian Chemical Society, 2020, vol. 31, no. 4, pp. 653-661. DOI: $0.21577 / 0103-5053.20190229$
22. Peredaran Y.V., Usol'tseva I.O., Krasnoschekova D.V. The core technology of obtaining magnesium oxide from serpentinite. Polzunovsky Vestnik, 2019, no. 2, pp. 123-127. DOI: 10.25712/ASTU.2072-8921.2019.02.024 In Rus.

23. Sirota V., Selemenev V., Kovaleva M., Pavlenko I., Mamunin K., Dokalov V., Yapryntsev M. Preparation of crystalline $\mathrm{Mg}(\mathrm{OH})_{2}$ nanopowder from serpentinite mineral. International Journal of Mining Science and Technology, 2018, vol. 28, Iss. 3, pp. 499-503. DOI: 10.1016/j.jimst.2017.12.018

24. Sierra C., Chouinard S, Pasquier L.C., Mercier G., Blais J.F. Feasibility study on the utilization of serpentine residues for $\mathrm{Mg}(\mathrm{OH})_{2}$ production. Waste Biomass Valor, 2018, vol. 9, pp. 1921-1933. DOI 10.1007/s12649-017-9926-9

25. Arce G.L.A.F., Neto T.G.S., Ávila I., Luna C.M.R., dos Santos J.C., Jr J.A.C. Influence of physicochemical properties of Brazilian serpentinites on the leaching process for indirect $\mathrm{CO}_{2}$ mineral carbonation. Hydrometallurgy, 2017, vol. 169, pp. 142-151. DOI: 10.1016/j.hydromet.2017.01.003

26. Malyshev A.V., Kislov E.V. Petrologo-geokhimicheskie aspekty Kholbyn-Khairkhanskogo giperbazitovogo plutona (Vostochny Saian) [Petrological-geochemical issues of the Kholbyn-Khairkhan ultramafic pluton, Eastern Sayan]. Metallogeniya drevnikh $i$ sovremennykh okeanov-2017. Differentsiatsiya $i$ prichiny raznoobraziya rudnykh mestorozhdenii. Nauchnoe izdanie [Metallogeny of ancient and modern oceans-2017. Differentiation and reasons of diversity of ore deposits. Scientific edition]. Miass, IMin UB RAS, 2017. pp. 221-224.

27. Malyshev A.V., Kislov E.V. Geologiya Ulan-Khodinskogo mestorozhdeniya apoultramafitovogo nefrita (yugo-vostochnaya chast Vostochnogo Sayana) [Geology of the Ulan Khoda nephrite deposit in the southeastern part of East Sayan]. Metallogeniya drevnikh $i$ sovremennykh okeanov-2015. Mestorozhdeniya okeanicheskikh struktur: geologiya, mineralogiva, geokhimiya $i$ usloviya obrazovaniya. Nauchnoe izdanie [Metallogeny of ancient and modern oceans-2015. Mineral Deposits of Oceanic Structures: Geology, Mineralogy, Geochemistry, and Formation Conditions. Scientific edition]. Miass, IMin UB RAS, 2015. pp. 220-223.

28. Portnov A.M., Dronova N.D. Unique nephrite. Priroda, 2016, no. 12 , pp. 18-23. In Rus.

29. Golik V.I., Komashchenko V.I., Rasorenov Yu.I. Activating components of hardening mixtures by underground mining ores. Izvestiva Tula State University, 2017, vol. 3, pp. 113-123. In Rus.

30. Burenina O.N., Davydova N.N., Andreeva A.V., Savvinova M.E. Influence of a way of crushing on activity of ingredients of concrete mix. Scientific Journal of KubSAU, 2015, no. 111 (07), Available at: http://ej.kubagro.ru/2015/07/pdf/70.pdf (accessed 11 February 2020). In Rus.

31. Prikhodov D.A., Baranov V.N., Nikiforova E.M., Gilmanshina T.R. Study of influence at physical and mechanical properties at activating of Portland cement. Fundamental Research, 2016, no. 11, pp. 938-943. In Rus.

Received: 26 December 2019.

\section{Information about the aurhors}

Liudmila I. Khudyakova, Dr. Sc., senior researcher, Baikal Institute of Nature Management Siberian Branch of the Russian Academy of Sciences.

Evgeniy V. Kislov, Cand. Sc., head of the laboratory, Geological institute Siberian Branch of the Russian Academy of Sciences.

Pavel L. Paleev, Cand. Sc., researcher, Baikal Institute of Nature Management Siberian Branch of the Russian Academy of Sciences.

Alexey V. Malyshev, engineer, Geological Institute Siberian Branch of the Russian Academy of Sciences. 